\title{
A Migração Venezuelana no Brasil: crise humanitária, desinformação e os aspectos normativos
}

Recebido: $17-11-2018$

Aprovado: 29-02-2019

Antônio Tadeu Ribeiro de Oliveira ${ }^{1}$

\section{Introdução}

A proposta deste artigo é apresentar um panorama geral sobre a recente imigração venezuelana para o Brasil, destacando aspectos relacionados aos fatores que impulsionaram os fluxos migratórios, as condições no destino, o perfil dos imigrantes, a desinformação como forma de colocar essa migração como ameaça, as debilidades no acolhimento e os aspectos normativos.

A produção teórica a respeito desse fenômeno é muito restrita, o que se tem são estudos empíricos sobre os imigrantes venezuelanos em Roraima. Isso faz com que se recorra a matérias jornalísticas e aos registros administrativos para que seja possível compor um quadro mais amplo sobre essa imigração.

Um olhar não muito atento tenderia a dizer que se trata de migração forçada, segundo a visão de Jubilut e Madureira (2014) e Milesi (2015), tendo em vista o elevado volume de pedidos de refúgio, ou que se está diante de fluxos mistos, na perspectiva de Silva et al. (2017), face à presença de migrantes econômicos e solicitantes de refúgio na mesma corrente migratória. A pesquisa conduzida pela Cátedra Sergio Vieira de Mello, da Universidade Federal de Roraima (UFRR) e o Observatório das Migrações Internacionais (OBMigra) (SIMÕES et al, 2017) apontou, como será detalhado no subtítulo 3, que uma minoria das pessoas foi posta em movimento em decorrência de perseguição ou ameaça política. A larga maioria buscava escapar do desemprego, inflação, desabastecimento de produtos básicos, que,

\footnotetext{
1 Pós-Doutor pela Universidad Complutense de Madrid, Doutor em Demografia pelo IFCH/UNICAMP; Pesquisador em Informações Geográficas e Estatísticas do Instituto Brasileiro de Geografia e Estatística (IBGE); Pesquisador Associado Observatório das Migrações Internacionais (OBMigra/UnB). Brasil. Email: tadeu.cidade@gmail.com
} 
no limite, levava à fome. No momento da pesquisa, a situação de fome aparecia como um marcador da migração.

Enfim, ainda há muito o que se investigar para que possa construir um arcabouço teórico que minimamente se aproxime dessa realidade. Aqui esses deslocamentos serão tratados como migração laboral, forçada por uma crise humanitária descomunal que tem raízes em problemas políticos, econômicos e sociais. A gravidade da situação requer das autoridades brasileiras, nas três esferas de governo (federal, estaduais e municipais), que seja dado um acolhimento digno e facilitada a integração de nossos irmãos e irmãs venezuelanos no Brasil.

\section{Antecedentes - a crise humanitária na Venezuela e a emigração}

As crises política, social e econômica que vêm afetando a Venezuela, e intensificadas na segunda metade da atual década, colocou a emigração internacional como alternativa de sobrevivência para aproximadamente dois milhões de venezuelanos, segundo o Alto Comissariado das Nações Unidas para os Refugiados (G1, 2018a). O Brasil é um entre os muitos destinos desses migrantes. Os graves fatores geradores desses deslocamentos populacionais acabaram por se traduzir numa verdadeira crise humanitária.

A Venezuela, durante a maior parte do governo de Hugo Chávez (1999-2013), viveu anos de prosperidade econômica e social. Com uma economia $90 \%$ dependente da produção/exportação do petróleo, num período que o preço médio do barril superava U\$100 (cem dólares), era possível adotar programas sociais de transferência de renda, de melhorias na qualidade dos serviços de educação e saúde, além de construção de moradias populares. Essas ações pavimentavam o caminho na busca da transformação da sociedade venezuelana do modo de produção capitalista para o socialismo bolivariano, inspirado na experiência cubana e nos movimentos históricos de resistência liderados por Simón Bolívar, que levaram à independência da América Espanhola.

No início da presente década, à medida que avançavam nacionalizações de empresas transnacionais e o Estado ampliava sua participação na economia como um todo, com destaque para o papel centralizador do Banco Central venezuelano, a oposição, liderada por empresários capitalistas, começou a intensificar a disputa por espaço de poder com fortes mobilizações, além de aliar-se ao capital internacional, buscando um cerco à economia daquele país. A resposta do governo foi igualmente dura: instaurou processo de perseguição 
aos líderes oposicionistas, dando início à espiral de violência, que culminou com as manifestações ao longo do ano de 2017.

Em 2013, dois fatores foram fundamentais para o início do agravamento nas condições econômica, política e social na Venezuela: o de ordem econômica dizia respeito ao movimento de queda no preço do barril de petróleo, principal commodity venezuelana; o de natureza política estava associado à doença e posterior falecimento do principal líder político do país, o Comandante Chávez. As questões sociais deterioraram em função da combinação da falta de recursos para investimentos nos programas de transferência de renda, escassez de alimentos e inflação alta, aliadas à falta de liderança política representada pela ausência do Comandante, que abria perspectiva mais factível de mudança de poder.

Num quadro de adversidades econômicas, políticas e sociais a migração internacional resultava como estratégia importante de sobrevivência para milhões de venezuelanos, que começaram a deixar o país em maior intensidade a partir de 2015. Entre os principais destinos da emigração venezuelana, de acordo com dados da 800 Noticias (2018), o Brasil surge em $7^{\circ}$ lugar na preferência dos emigrantes, bem distante de Colômbia (550 mil), Equador (288 mil), Panamá (269 mil), Espanha (250 mil) e Chile (164 mil). As estimativas sobre a presença venezuelana em território brasileiro apresentam variação muito grande, algo entre 40 a 80 mil imigrantes daquela nacionalidade, tema que também será abordado com mais detalhe no subtítulo 4. Todavia, se considerado o maior valor, os volumes seriam próximos aos observados no Peru (100 mil). No patamar inferior, a aproximação se daria com Argentina (31 mil) e Estados Unidos (30 mil).

Segundo matéria jornalística de Colombo (2018), a emigração venezuelana se distingue de outros fluxos observados na região pela intensidade e velocidade com que ocorreram os deslocamentos. A reportagem menciona que aproximadamente cinco por cento da população havia migrado desde 2014 até setembro de 2018. Citando o cientista político do Instituto Di Tella, Juan Toklatian, o periodista aponta duas características importantes dessa migração: além da rapidez e do volume, os movimentos de população ocorreram num curto espaço de tempo; os países da região não estavam preparados para receber os imigrantes.

No caso brasileiro, foi observada a imigração de indígenas da etnia Warao e não indígenas. Os indígenas se distribuíram por Pacaraima, Boa Vista, Manaus e, em menor medida, Belém. Enquanto, num primeiro momento, a população não indígena se dirigiu, basicamente, para Boa Vista, solicitando refúgio ou visto de residência temporária. 
Os fluxos migratórios, inicialmente, começaram a chegar ao Brasil em 2015 através do município de Pacaraima, cidade de fronteira localizada no noroeste de Roraima. Contudo, apenas mais recentemente, entre 2017 e 2018, é que os fluxos se intensificaram, sendo notado o ingresso em volumes importantes que chegam, por via área, através dos aeroportos internacionais de São Paulo e Rio de Janeiro.

\section{As Condições no Destino e o Perfil dos Imigrantes}

Pacaraima, no estado de Roraima, se localiza na fronteira com a província de Bolívar, na Venezuela. Como o município não apresenta condições favoráveis ao acolhimento dessa migração, os venezuelanos seguem em direção à capital do estado, em Boa Vista, que com o passar do tempo e a intensificação dos fluxos também viu esgotada sua capacidade de recepção, sobretudo pela pressão nos serviços de saúde e assistência social. Nem o estado de Roraima, muito menos seus municípios, possuem condições de receber fluxos migratórios volumosos como os vêm do país vizinho.

Por mais paradoxal que pareça, os emigrantes venezuelanos deixam um país que, no ano de 2016, tinha aproximadamente $90 \%$ de população vivendo em áreas urbanas, taxa de mortalidade infantil de 13,8\%o, esperança de vida ao nascer de 75,4 anos, e Índice de Desenvolvimento Humano (IDH) de 0,767. Ao chegarem ao Brasil, ingressam por um estado com 522,6 mil de habitantes, sendo que destes 66,0\% vivem em zonas urbanas; $70 \%$ do território é composto por terras indígenas e reservas ambientais; onde a principal atividade econômica é a prestação de serviços (87,5\%), com destaque para o serviço público (75\%), indústria $(8,7 \%)$ e agropecuária $(3,8 \%)$; o Produto Interno Bruto (PIB) corresponde a $0,1 \%$ do PIB brasileiro; situação que acaba por refletir em seus indicadores sociodemográficos: esperança de vida ao nascer de 71,5 anos, taxa de mortalidade infantil de 17,2\%o e IDH de 0,707 .

Por sua vez, a capital Boa Vista, para onde se destina a maior parcela da migração, tem aproximadamente 322,0 mil de habitantes, esperança de vida ao nascer de 74,0 anos, taxa de mortalidade infantil de $13,8 \%$ e IDH de 0,752 e economia baseada no comércio, prestação de serviço e indústria.

Para completar o quadro do lugar de principal destino da migração, o Roraima é o único estado brasileiro que não recebe energia elétrica do sistema nacional, sendo que grande parte do seu abastecimento vem da Venezuela.

Revista de Estudos e Pesquisas sobre as Américas V.13 N.1 2019 ISSN: 1984-1639 
Em resumo, só mesmo uma situação desesperadora poderia levar à opção de emigrar para Roraima e, em seguida, se se dirigir à Boa Vista, dado que as condições objetivas no destino não seriam as melhores para acolher fluxos migratórios de tal magnitude. Do ponto de vista do desenvolvimento econômico, nem o estado, nem a sua capital, possuem capacidade de gerar empregos suficientes para inserir adequadamente a força de trabalho venezuelana. No aspecto social, a infraestrutura de serviços sociais básicos tampouco suporta o volume da migração observado. Mal comparando, a questão migratória no Norte do país, exceto pelas mortes na travessia, é mais delicada do que àquela verificada na Europa, se levados em consideração a proporção dos fluxos em relação à população local e o estágio de desenvolvimento nos países para onde se dirigem.

Essas dificuldades reais na capacidade de acolhimento acabaram por alimentar uma narrativa, por parte das autoridades locais, tanto no nível estadual quanto municipais, que colocava a imigração venezuelana como uma ameaça e algo extremamente negativo, chegando ao ponto de, por mais de uma vez, solicitarem o fechamento da fronteira com a Venezuela. As consequências práticas do discurso negativo foi produzir, numa parcela da população local ${ }^{2}$, uma certa aversão ao venezuelano, que passava a ser visto como o "outro indesejável”.

\section{O Perfil da Imigração Venezuelana}

Simões et al (2017) realizaram uma pesquisa que buscou traçar o perfil dos migrantes venezuelanos em Boa Vista e Pacaraima. Em realidade, foram dois levantamentos: um de caráter qualitativo, direcionado aos imigrantes indígenas da etnia Warao que viviam nos dois municípios; e outro de cunho quantitativo, através de aplicação de amostragem probabilística, voltado aos não indígenas residentes na capital do estado. $\mathrm{O}$ trabalho de campo foi realizado entre os meses de junho e agosto de 2017 e trouxe achados importantes a respeito dos dois coletivos investigados.

Em relação aos Waraos, a maioria partiu da região de Tucupita, percorrendo cerca de 700 quilômetros para chegar à fronteira brasileira. Parte ingressa no país pelos postos de fronteira e os demais pela serra. Da mesma forma, duas opções são adotadas para alcançarem

\footnotetext{
${ }^{2} \mathrm{O}$ discurso negativo teve adesão de uma parte apenas da população, dado que, sobretudo em Boa Vista, a distribuição de alimentos, organizada por vários moradores, foi de fundamental importância na sobrevivência dos venezuelanos que estavam fora do alcance das políticas públicas.
}

Revista de Estudos e Pesquisas sobre as Américas V.13 N.1 2019 ISSN: 1984-1639 
Boa Vista: uma caminhada exaustiva de mais de 200 quilômetros ou por transporte rodoviário, no caso daqueles com algum recurso financeiro.

Reportaram que o principal motivo de emigrarem foi a fome, mas acrescentaram a dificuldade de acesso aos serviços públicos de saúde e educação e o descaso do governo venezuelano com os indígenas.

Quando mencionam o projeto migratório,

... os relatos apontam que deixaram parte da família na Venezuela, com a função de cuidar dos bens materiais e migraram acompanhados de outra parte da família, com o intuito de enviar recursos. É constante a preocupação com os entes familiares, lamentam a falta de informação sobre os que ficaram e expressam a vontade de trazê-los para o Brasil (SIMÕES et al, 2017).

No Brasil, os Waraos se moveram entre os municípios de Pacaraima e Boa Vista, além de Manaus, no estado do Amazonas, e também em Belém, no estado do Pará. Contudo, na ocasião do levantamento, eles afirmavam não pretender reemigrar para outras cidades e já se observava o retorno para Boa Vista de famílias que estavam em Manaus.

Quanto à inserção laboral, os coletivos apresentavam comportamentos distintos, de acordo com o lugar de destino. Em Boa Vista, a maioria masculina não exercia qualquer atividade econômica, ao passo que as mulheres reproduziam o que faziam na Venezuela: pedir doações, fazer artesanato e costura. Em Pacaraima, os homens trabalhavam no mercado informal, principalmente na carga e descarga de caminhões, além de limpeza de fazendas e terrenos. Já as mulheres estavam menos inseridas nas atividades produtivas.

Em relação ao projeto futuro, a maioria dos residentes em Boa Vista queriam permanecer na cidade e trazer seus familiares. Os demais retornariam à Venezuela, caso a situação naquele país melhorasse.

O levantamento quantitativo, que tinha como população alvo os imigrantes não indígenas, revelou que a migração se constituía, predominantemente, de homens jovens, em idade de trabalhar $(62,9 \%)$, e solteiros $(54,0 \%)$, como pode ser observado na Tabela 1.

Tabela 1

Revista de Estudos e Pesquisas sobre as Américas V.13 N.1 2019 ISSN: 1984-1639 
Imigrantes venezuelanos, não indígenas, por sexo, segundo grupos de idade. Boa Vista - 2017

\begin{tabular}{l|ccc}
\hline \multirow{2}{*}{ Grupos de idade } & \multirow{2}{*}{ Total } & \multicolumn{2}{|c}{ Sexo } \\
\cline { 3 - 4 } & & Homens & Mulheres \\
\hline \hline \multicolumn{1}{c}{ Total } & $\mathbf{1 0 0 , 0}$ & $\mathbf{6 2 , 9}$ & $\mathbf{3 7 , 1}$ \\
18 a 19 & 3,0 & 1,9 & 1,1 \\
20 a 39 & 72,9 & 46,6 & 26,2 \\
40 a 64 & 23,2 & 13,9 & 9,4 \\
65 e mais & 0,9 & 0,5 & 0,5 \\
\hline
\end{tabular}

Fonte: Simões et al. 2017.

Eram pessoas com alto nível de escolaridade, 62,4\% com, no mínimo, nível médio completo, sendo que desses $31,9 \%$ possuía superior completo (Tabela 2). São indicadores muito superiores aos observados na população brasileira, sobretudo quando comparados aos dos residentes em Boa Vista.

Tabela 2

Imigrantes venezuelanos, não indígenas, por sexo, segundo escolaridade. Boa Vista - 2017

\begin{tabular}{lcccc}
\hline \multirow{2}{*}{ Escolaridade } & \multirow{2}{*}{ Total } & \multicolumn{2}{c}{ Sexo } \\
\cline { 3 - 4 } & & Homens & Mulheres \\
\hline \hline \multirow{1}{c}{ Total } & $\mathbf{1 0 0 , 0}$ & $\mathbf{6 2 , 9}$ & $\mathbf{3 7 , 1}$ \\
Analfabeto & 0,9 & 0,3 & 0,6 \\
Ensino fundamental completo & 4,8 & 3,7 & 1,1 \\
Ensino fundamental incompleto & 2,3 & 1,8 & 0,5 \\
Ensino médio completo & 30,5 & 19,4 & 11,1 \\
Ensino médio incompleto & 14,0 & 9,4 & 4,6 \\
Ensino superior completo & 28,4 & 16,8 & 11,6 \\
Ensino superior incompleto & 15,6 & 9,6 & 6,0 \\
Pós-graduado (Esp/mestr/dout) & 3,5 & 1,8 & 1,7 \\
\hline
\end{tabular}

Fonte: Simões et al. 2017.

Em suma, o perfil da imigração venezuelana cujas principais caraterísticas eram a de homens e mulheres em idade ativa, majoritariamente solteiros, de pessoas com excelente nível educacional, sinaliza um potencial de força de trabalho que muito poderá vir a contribuir com o desenvolvimento econômico e social do país, ademais de agregar valores como a diversidade cultural e gastronômica. 
Quando se buscou investigar a origem da emigração em território venezuelano e como estavam inseridos no mercado laboral em seus lugares de moradia anterior, identificou-se que os deslocamentos partiram de diversas províncias, com destaque para Bolívar (26,8\%), Monagás (16,6\%) e Caracas (15,6\%). Em relação à ocupação, cerca de 73,0\% relatou possuir trabalho na Venezuela. Ao serem perguntados sobre o principal motivo que os fazia emigrar, a ampla maioria indicou a crise econômica e a crise política $(76,7 \%)$, como demonstrado na Tabela 3.

Tabela 3

Imigrantes venezuelanos, não indígenas, por sexo, segundo motivo da emigração. Boa Vista - 2017

\begin{tabular}{l|c|c|c}
\hline \multirow{2}{*}{ Motivo da emigração } & \multirow{2}{*}{ Total } & \multicolumn{2}{c}{ Sexo } \\
\cline { 3 - 4 } & & Homens & Mulheres \\
\hline \hline \multirow{1}{c}{ Total } & $\mathbf{1 0 0 , 0}$ & $\mathbf{6 2 , 9}$ & $\mathbf{3 7 , 1}$ \\
Crise política & 25,5 & 17,0 & 8,5 \\
Crise econômica & 51,2 & 30,8 & 20,4 \\
Busca de trabalho & 12,4 & 8,8 & 3,6 \\
Outros motivos & 10,8 & 6,2 & 4,6 \\
\hline
\end{tabular}

Fonte: Simões et al. 2017.

A pergunta sobre o status migratório é reveladora da estratégia adotada para a entrada no território brasileiro, o que não difere muito do observado dos fluxos que partem da África e Oriente Médio em direção à Europa e mesmo pelos deslocamentos de latino-americanos que buscam entrar nos Estados Unidos, quando migrantes laborais ou fugindo de crises humanitárias recorrem ao argumento do refúgio para terem o ingresso no país de destino facilitado.

Tabela 4 
Imigrantes venezuelanos, não indígenas, por sexo, segundo status migratório. Boa Vista - 2017

\begin{tabular}{l|c|c|c}
\hline \multirow{2}{*}{ Status migratório } & \multirow{2}{*}{ Total } & \multicolumn{2}{c}{ Sexo } \\
\cline { 3 - 4 } & & Homens & Mulheres \\
\hline \multicolumn{1}{c}{ Total } & $\mathbf{1 0 0 , 0}$ & $\mathbf{6 2 , 9}$ & $\mathbf{3 7 , 1}$ \\
Solicitante de refúgio & 82,9 & 51,9 & 31,0 \\
Solicitante de residência & 5,6 & 3,4 & 2,2 \\
Sem documentos & 7,1 & 4,7 & 2,5 \\
Outros & 4,3 & 2,9 & 1,4 \\
\hline
\end{tabular}

Fonte: Simões et al. 2017.

Ao serem combinadas as perguntas sobre participação no mercado de trabalho, motivação para emigrar e status migratório, dois aspectos devem ser ressaltados: i) a maioria que possuía trabalho se deparava com dificuldades de acessar produtos de primeira necessidade, como alimentos, remédios, etc., além de conviver com elevados índices de inflação que diminuíam poder de compra. A associação entre esses aspectos, em muitos casos, levava à fome e à desnutrição, daí a crise econômica ser apontada como a principal motivação para 51,2\% dos imigrantes; o segundo aspecto está relacionado ao status migratório reivindicado por amplo contingente dos venezuelanos, como visto acima, 82,9\% eram solicitantes de refúgio (Tabela 4). Mesmo se todos que indicaram a crise política como fator de expulsão (25,5\%) tivessem sido perseguidos pelo Regime de Maduro ou sofrido fundado temor de perseguição, parcela substantiva não teria a solicitação de refúgio concedida. Essa situação colocou uma importante questão a ser enfrentada pelo governo brasileiro: que procedimentos adotar para criar normativas legais que permitissem a regularização dessa migração.

Os deslocamentos dos venezuelanos tinham um forte caráter familiar: 56,4\% migrou com algum familiar, sendo que as $42,8 \%$ das mulheres veio acompanhada dos filhos menores, o que as colocava em situação de maior vulnerabilidade.

Um outro elemento complicador para a integração dos migrantes estava relacionado ao idioma, dado que 77,3\% não dominava o português e 61,5\% não falava outra língua que não o espanhol. Em parte, essa dificuldade foi amenizada pela rede migratória que afirmavam possuir no país, uma vez que 59,8\% sinalizaram conhecer alguém que já se encontrava em território brasileiro, em maior medida, amparavam-se em amigos $(58,0 \%)$.

Naquela ocasião, um pouco mais da metade dos migrantes acessavam algum tipo de serviço público em Boa Vista, em grande parte os de saúde (Tabela 5). Contudo, essa pressão 
já era suficiente para que as autoridades locais se manifestassem no sentido de afirmar que o atendimento estaria entrando em colapso. A demanda pelos serviços públicos foi o grande mote para colocar em marcha a narrativa sobre o quanto a migração venezuelana era indesejada e ameaçadora para a ordem de Roraima e de sua capital.

Tabela 5

Imigrantes venezuelanos, não indígenas, por sexo, segundo tipo de serviço acessado. Boa Vista - 2017

\begin{tabular}{l|c|c|c}
\hline \multirow{2}{*}{ Tipo de serviço acessado } & \multirow{2}{*}{ Total } & \multicolumn{2}{|c}{ Sexo } \\
\cline { 3 - 4 } & & Homens & Mulheres \\
\hline \hline \multirow{2}{*}{ Total } & $\mathbf{1 0 0 , 0}$ & $\mathbf{6 1 , 6}$ & $\mathbf{3 8 , 4}$ \\
Saúde & 38,9 & 23,6 & 15,3 \\
Educação & 10,4 & 5,4 & 5,0 \\
Assistência social & 2,2 & 1,4 & 0,8 \\
Nenhum & 48,4 & 31,2 & 17,2 \\
\hline
\end{tabular}

Fonte: Simões et al. 2017.

Mesmo com todas barreiras colocadas pelo idioma e o estereótipo de serem perturbadores da ordem local, 60,6\% possuía alguma atividade remunerada, trabalhava mais de 40 horas semanais $(52,1 \%$ ), com a maioria recebendo entre 1 e 2 salários mínimos (Tabela $6)$.

Tabela 6

Imigrantes venezuelanos, não indígenas, por sexo, segundo remuneração recebida (sál. mínimo). Boa Vista - 2017

\begin{tabular}{l|c|c|c}
\hline \multirow{2}{*}{ Remuneração recebida } & \multirow{2}{*}{ Total } & \multicolumn{2}{|c}{ Sexo } \\
\cline { 3 - 4 } & & Homens & Mulheres \\
\hline \multicolumn{1}{c}{ Total } & $\mathbf{1 0 0 , 0}$ & $\mathbf{6 4 , 1}$ & $\mathbf{3 5 , 9}$ \\
menos de 1 salário mínimo & 50,4 & 29,2 & 21,2 \\
de 1 a 2 salários mínimos & 44,0 & 30,3 & 13,7 \\
acima de 2 salários mínimos & 4,8 & 3,8 & 1,0 \\
Nenhum & 0,8 & 0,8 & 0,0 \\
\hline
\end{tabular}

Fonte: Simões et al. 2017. 
Merece destaque o fato de que apesar de mal remunerados, os imigrantes que possuíam trabalho enviavam para Venezuela remessas superiores a $\mathrm{R} \$ 100,00^{3}$, sendo os principais destinatários pais e filhos $(73,9 \%)$, que, por sua vez, utilizavam os recursos para gastos com as despesas da família.

As manifestações de preconceito e discriminação também já se faziam notar. Mais de 1/3 dos venezuelanos já havia sofrido algum tipo de discriminação, em grande medida, por serem estrangeiros, sendo identificado como principal agressor um brasileiro comum. Além disso, 20,3\% tinha percebido alguma forma de tratamento diferenciado no local de trabalho, sendo o mais comum deles, novamente, a simples razão de serem estrangeiros. Tudo leva a crer que os sinais negativos que partiam das autoridades locais, a respeito da imigração venezuelana, acabaram por contaminar o comportamento de parte da população, que passou a se comportar de modo agressivo em relação aos imigrantes.

A partir da preocupação do governo central com a incapacidade objetiva de Boa Vista acolher adequadamente os imigrantes, a pesquisa procurou saber como os venezuelanos encaravam a possibilidade de migrarem para outros municípios brasileiros, caso recebessem auxílio estatal. Na Tabela 7 pode-se observar que 78,0\% aceitaria se interiorizar desde que tivessem suporte do governo brasileiro, de preferência com oferta de trabalho $(79,6 \%)$. Um outro dado interessante, obtido entre aqueles que queriam permanecer na cidade, é que esses estavam entre os menos escolarizados e as razões para permanência se dividia entre ficar próximo à fronteira e o argumento que já estavam integrados à sociedade local. Esses dados sugerem que quanto mais vulnerável, maior o receio de se distanciar do país de origem. Muito provavelmente, a alegada integração pode estar associada ao trabalho no mercado informal, que, apesar de remunerar mal, garantia algum recurso de sobrevivência e, até mesmo, auxiliar quem permaneceu na Venezuela, por intermédio do envio de remessas ou bens de primeira necessidade.

Tabela 7

\footnotetext{
${ }^{3}$ Isso correspondia a mais de US\$ 30 em valores da época.

Revista de Estudos e Pesquisas sobre as Américas V.13 N.1 2019 ISSN: 1984-1639
} 
Imigrantes venezuelanos, não indígenas, por sexo, segundo vontade de se interiorizar, caso o governo brasileiro ajudasse.

\begin{tabular}{l|c|c|c}
\multicolumn{4}{c}{ Boa Vista - 2017} \\
\hline \multirow{2}{*}{ Vontade de interiorizar } & \multirow{2}{*}{ Total } & \multicolumn{2}{c}{ Sexo } \\
\cline { 3 - 4 } & & Homens & Mulheres \\
\hline \hline \multirow{2}{*}{ Total } & $\mathbf{1 0 0 , 0}$ & $\mathbf{6 2 , 9}$ & $\mathbf{3 7 , 1}$ \\
Sim & 78,0 & 51,3 & 26,7 \\
Não & 15,1 & 7,6 & 7,5 \\
Não sabe & 6,9 & 4,0 & 2,9 \\
\hline
\end{tabular}

Fonte: Simões et al. 2017.

Quando foram indagados sobre a possibilidade de retorno à Venezuela e quais seriam as condições necessárias para a volta à terra natal, apenas $25,1 \%$ disse querer regressar. Entre esses, $46,6 \%$ apontou que isso poderia ocorrer num prazo superior a dois anos, condicionando o retorno à melhoria das condições econômicas $(61,3 \%)$.

Para os que intencionavam permanecer no Brasil, o projeto migratório passava, fundamentalmente, pela obtenção de trabalho $(63,3 \%)$ e, em menor medida, pela abertura do próprio negócio, mostrando o lado empreendedor de 14,7\% dos imigrantes, conforme dados da tabela abaixo.

\section{Tabela 8}

Imigrantes venezuelanos, não indígenas, por sexo, segundo principal objetivo caso permaneça no Brasil . Boa Vista - 2017

\begin{tabular}{l|c|c|c}
\hline \multirow{2}{*}{ Principal objetivo } & \multirow{2}{*}{ Total } & \multicolumn{2}{c}{ Sexo } \\
\cline { 3 - 4 } & & Homens & Mulheres \\
\hline \multicolumn{1}{c}{ Total } & $\mathbf{1 0 0 , 0}$ & $\mathbf{6 2 , 8}$ & $\mathbf{3 7 , 2}$ \\
Conseguir um bom trabalho & 63,3 & 40,9 & 22,3 \\
Fazer curso superior & 9,1 & 5,4 & 3,7 \\
Fazer cursos de capacitação & 8,1 & 4,5 & 3,6 \\
Abrir o próprio negócio & 14,7 & 9,1 & 5,6 \\
Outros & 4,8 & 2,8 & 2,0 \\
\hline
\end{tabular}

Fonte: Simões et al. 2017.

Além da pesquisa conduzida por Simões et al. (2017), outra investigação de porte foi levada a campo, entre janeiro e março de 2018, fruto da parceria entre a Organização Internacional para as Migrações (OIM) e o Ministério dos Direitos Humanos (MDH). O 
Monitoramento do Fluxo Migratório Venezuelano (DTM-Brasil, 2018), corroborou, de um modo geral, os dados levantados pela UFRR/OBMigra, sobretudo no que dizia respeito ao perfil sociodemográfico dos imigrantes. Quando a DTM foi divulgada, o grande destaque era o fato de $58 \%$ dos migrantes não desejarem permanecer no Brasil e entre os $48 \%$ que queriam ficar, apenas $22 \%$ tinham Roraima como lugar de destino, e $59 \%$ pretendiam se dirigir ao Amazonas. Contudo, como veremos a seguir, a realidade vem frustrando esses resultados, dado que a maioria dos venezuelanos se concentra no estado de Roraima, com São Paulo surgindo como segundo lugar de destino dessa migração ${ }^{4}$.

Outros dados que reforçam a importância e a dinâmica da imigração venezuelana vêm dos registros administrativos, como por exemplo: são a quinta nacionalidade em emissão de carteiras, foram quase 19 mil, entre 2015 e junho de 2018 (OBMIGRA, 2018); aproximadamente 2.000 desses imigrantes já estavam inseridos no mercado de trabalho formal, ao final de 2017 (OBMIGRA, 2017); do ponto de vista da movimentação, nesse mesmo mercado, os venezuelanos passaram a ser a segunda nacionalidade, uma vez que até junho de 2018, foram 2.315 admissões e 1.028 demissões (OBMIGRA, 2018). Essas informações permitem inferir que até a metade do corrente ano seriam cerca de 3.200 trabalhadores venezuelanos empregados no mercado formal.

\section{A Desinformação como Combustível para Intolerância}

Uma das principais características que tem marcado o enfrentamento dessa questão é a falta de informação ou informações desencontradas, que acabam por produzir mitos a respeito do volume de venezuelanos que aporta ao território brasileiro. Esse tipo de comportamento, sobretudo por parte das autoridades estaduais e municipais, longe de ajudar na mitigação dos problemas, produz uma onda de preconceito e xenofobia contra os imigrantes.

Quando os fluxos começaram a se intensificar, em 2016, ingressando por Pacaraima, as autoridades noticiavam que cerca de 600 venezuelanos chegavam por dia ao município. Considerando que a cidade possuía cerca de 12 mil habitantes, bastariam 20 dias para que a população duplicasse de tamanho e toda infraestrutura municipal públicos entrasse em colapso. Essa foi a primeira mensagem alarmista emitida pelos governantes locais.

\footnotetext{
${ }^{4}$ Um possível viés observado na DTM pode estar associado à ponderação da amostra por município, ao dar peso grande para as entrevistas realizadas no município de Pacaraima, além de ter concentrado boa parte do trabalho de campo em locais como o terminal rodoviário e o aeroporto de Boa Vista.
} 
Um olhar mais cauteloso, apontava que uma parcela daquelas pessoas vinha apenas para comprar alimentos, remédios e outros produtos, retornava em seguida para Venezuela, outra parte se dirigia a Boa Vista, restando um número menor de indivíduos permanecia naquele município. Tanto é assim que apenas com a chegada dos indígenas, da etnia Warao, em 2017, um volume maior de venezuelanos passou a ser percebido no local.

Com o aumento da migração venezuelana, e sua concentração em Boa Vista, uma nova cifra mágica passou a vigorar: seriam 30 mil os imigrantes. Em meados de 2017, pesquisadores da Universidade Federal de Roraima e do OBMigra (SIMÕES, 2017) fizeram um estudo que, entre outros achados, apontava que apenas $20 \%$ dos venezuelanos residentes naquela cidade ainda não havia procurado o Departamento de Polícia Federal (DPF) visando regularização, via solicitação de refúgio ou visto de residência temporária. Como àquela altura cerca de 13 mil pedidos haviam sido direcionados ao DPF, uma estimativa mais realista sobre o volume de migrantes deveria ser da ordem 16,3 mil, ou seja, um pouco mais da metade do número alardeado pelas autoridades locais.

Mais recentemente, em 2018, as estimativas passaram a variar entre 40 e 80 mil pessoas. Propagavam-se notícias de que, em média, 500 pessoas chegavam por dia à capital do estado. Se essas cifras estivessem corretas, de janeiro a junho, desse mesmo ano, teriam migrado para o estado 90.500 venezuelanos. Segundo se disseminava, Boa Vista estaria vivenciando o "verdadeiro inferno na terra", com os serviços públicos sendo pressionados, aumento da violência, etc. No meio disso tudo, a realização de um "censo" para enumerar os imigrantes foi anunciada pelas autoridades federais. Iniciativa que não passou do discurso, revelando o desconhecimento e a incapacidade de gestão pelos atores governamentais das três esferas de poder.

Pouco tempo depois, novos números foram divulgados: pesquisa divulgada pela prefeitura, em 18/06/2018, informava que 25 mil venezuelanos estariam vivendo na cidade (G1, 2018c); estimativas populacionais do IBGE davam conta de pouco mais de 30 mil venezuelanos residindo em Roraima, sendo 27.000 em Boa Vista (IBGE, 2018). Dados esses, mais fidedignos, que não ratificavam os volumes superdimensionados até então disseminados.

Se a intenção não fosse aprofundar o caos, a análise dos dados de registros administrativos, sob a gestão do Departamento de Polícia Federal, se não de forma exata, ajudaria a se ter uma ideia da real dimensão dos processos migratórios. Os registros de

\footnotetext{
${ }^{5} \mathrm{O}$ termo censo foi grifado entre aspas, uma vez que nem de longe a operação proposta do governo se assemelhava a uma operação censitária, dado que nem todos os imigrantes seriam enumerados.
}

Revista de Estudos e Pesquisas sobre as Américas V.13 N.1 2019 ISSN: 1984-1639 
entradas e saídas, que poderiam apontar inclusive os postos de fronteiras utilizados pelos venezuelanos para ingressar e deixar o território brasileiro; o número de solicitações de refúgio; o número de solicitação de visto de residência; e o volume de registros concedidos aos migrantes, com os respectivos lugares de residência, auxiliariam tremendamente uma melhor apreensão do fenômeno. Essas informações possibilitariam agregar um valor inestimável se as informações das bases mencionadas estivessem integradas.

A seguir são apresentados alguns números que poderiam ajudar no dimensionamento mais próximo da realidade em estudo.

Tabela $9^{6}$

Número de entradas e saídas de venezuelanos pela fronteira, segundo ano/mês, Brasil - 2015 - Jul/2018.

\begin{tabular}{c|c|c|c}
\hline Ano/mês & Entradas & Saídas & Saldo \\
\hline \hline Total & 393.974 & 304.993 & 88.981 \\
2015 & 78.833 & 74.670 & 4.163 \\
2016 & 87.546 & 80.042 & 7.504 \\
2017 & 101.320 & 74.031 & 27.289 \\
jan/2018 & 15.378 & 7.768 & 7.610 \\
fev/2018 & 15.760 & 9.234 & 6.526 \\
mar/2018 & 18.504 & 12.959 & 5.545 \\
abr/2018 & 18.437 & 12.619 & 5.818 \\
mai/2018 & 19.217 & 12.675 & 6.542 \\
jun/2018 & 18.233 & 10.750 & 7.483 \\
jul/2018 & 20.746 & 10.245 & 10.501 \\
\hline
\end{tabular}

Fonte: Elaboração própria, a partir dos dados do Sistema de Trafégo Internacional, 2018.

Apesar das chegadas terem sido percebidas a partir de 2015, a diferença entre entradas e saídas ratificam que o fenômeno ganha proporções consideráveis em 2017, com saldo superior a 27 mil movimentos; se expande e acentua em 2018, quando o balanço alcança os 50 mil, nos sete primeiros meses do ano.

Não obstante esses dados, desde 2016 já se propalava que mais de 500 venezuelanos chegavam por dia a Roraima. A rigor, levando-se em consideração os 365 dias do ano, em média, eram cerca de 240 entradas. Contudo, as saídas diárias do país eram 220.

\footnotetext{
${ }^{6}$ Como não há a identificação da pessoa, um mesmo indivíduo pode ter mais de um movimento de entrada e saída.
}

Revista de Estudos e Pesquisas sobre as Américas V.13 N.1 2019 ISSN: 1984-1639 
Outro dado interessante está associado aos postos de fronteira por onde transitam os venezuelanos (Tabela 10).

Tabela 10

Número de entradas e saídas de venezuelanos pela fronteira, segundo município, Brasil - jan/jul 2018.

\begin{tabular}{c|c|c|c}
\hline \multirow{2}{*}{ Município } & \multicolumn{3}{|c}{ Total } \\
\cline { 2 - 4 } & Entradas & Saídas & Saldo \\
\hline \hline Total & 126.275 & 76.250 & 50.025 \\
Guarulhos/SP & 9.191 & 19.710 & -10.519 \\
Pacaraima/RR & 101.954 & 26.989 & 74.965 \\
Rio de Janeiro/RJ & 3.195 & 6.375 & -3.180 \\
Manaus/AM & 7.899 & 4.879 & 3.020 \\
Brasília/DF & 423 & 3.529 & -3.106 \\
Porto Alegre/RS & 392 & 453 & -61 \\
Assis Brasil/AC & 198 & 1.487 & -1.289 \\
Outros & 3.023 & 12.828 & -9.805 \\
\hline
\end{tabular}

Fonte: Elaboração própria, a partir dos dados do Sistema de Trafégo Internacional, 2018.

Os dados apontam que em apenas dois postos de fronteira o balanço entre entradas e saídas é positivo. Em Pacaraima (74 965) e em Manaus (3 020). Uma primeira inferência que só pode fazer é que o Brasil tem sido utilizado, em boa medida, como espaço de trânsito dessa migração. A outra, também dentro da lógica do trânsito, é que, definitivamente, Pacaraima é lugar de passagem, com aproximadamente 1/3 dos que entraram por lá, saindo por outros pontos de fronteira, dado que o balanço até o meio do ano foi de 50 mil movimentações.

A Casa Civil da Presidência da República anunciou no início de setembro que, desde de 2015 até agosto de 2018, 75,4 mil venezuelanos teriam procurado o Departamento de Polícia Federal para se regularizar. Foram 46,7 mil solicitações de refúgio, 14,9 mil pedidos de visto de residência e 13,8 mil agendamentos. Possivelmente, se os dados fossem integrados e identificados, poder-se-ia chegar à conclusão que uma parcela desses indivíduos que solicitou regularização já reemigrou, seja retornando para Venezuela, seja se dirigindo a outro país.

Dados do DPF (2018) apontam que cerca de 20 mil registros foram concedidos a venezuelanos entre 2015 e agosto de 2018, sendo 88,6\% deles com base na Resolução 
Normativa, que concedeu visto de residência para migrantes oriundos de países fronteiriços que não fazem parte do Acordo sobre Residência para Nacionais dos Estados Partes do Mercado Comum do Sul - Mercosul, Bolívia e Chile. Do total de venezuelanos registrados, 69,1 \% se regularizou em Roraima e 8,7\% em São Paulo.

São números que dão medida mais aproximada do fenômeno, que, longe de minimizálo, sinalizam que: de alguma forma a questão está sendo equalizada; parte da migração, de forma espontânea, segue para outros estados ou até mesmo vai para outros países.

Enfim, desde que o fenômeno passou a ganhar expressão, nos meados de 2016, autoridades estaduais e municipais adotaram como estratégia amplificar os volumes da migração, pari pasu à disseminação de que se estava frente a uma ameaça à estabilidade econômica e social, particularmente, em Boa Vista. Como já mencionado, o estado e sua capital claramente não reúnem condições objetivas para acolher fluxos migratórios na magnitude dos observados. Todavia, o comportamento de quem tem a responsabilidade precípua para enfrentar questão, em nada ajudava. Até meados de 2017, a situação seria administrável, caso uma ação integrada, efetiva e coordenada entre os três entes federados tivesse sido colocado em prática, sobretudo no que tange ao acolhimento em locais com condições dignas e à política de interiorização, como era da vontade da maioria dos migrantes, tivesse sido prontamente implementada.

Todavia, não foi o que ocorreu. Medidas mais efetivas só foram implementadas no início de 2018, quando a situação estava fugindo totalmente do controle, com milhares de venezuelanos vivendo na rua, sem alimentação e os serviços públicos sem dar atendimento adequado. Nesse momento, começaram a chegar ajuda federal através das forças armadas, que iniciou, com apoio de organismos internacionais, especialmente, ACNUR, a construção de abrigos decentes, a distribuição de alimentos e a implementação de cuidados de saúde.

A impressão que se tem é a de que os números são reificados de modo a criar imagem negativa dos processos migratórios em curso, com duas finalidades principais: conseguir mais recursos junto ao governo federal e dar satisfação política aos eleitores, já contaminados com a propaganda contrária à imigração venezuelana, o que vem contribuindo de forma decisiva para a estigmatização dos imigrantes venezuelanos, seja em Pacaraima, seja em Boa Vista.

\section{As Medidas para o Acolhimento:}

Os aspectos normativos 
Não bastasse a falta de iniciativa dos entes federados para enfrentar essa questão migratória, que acabou por gerar uma crise humanitária de grandes proporções, a imigração venezuelana também foi em grande medida afetada pelos aspectos normativos.

$\mathrm{O}$ primeiro deles diz respeito à não assinatura pela Venezuela do Acordo sobre Residência para Nacionais dos Estados Partes do Mercado Comum do Sul - Mercosul, Bolívia e Chile. No âmbito da formação do bloco comunitário do Mercosul, o governo Chávez relutou em ser signatário da parte do Acordo que tratava do acesso aos vistos de residência para os indivíduos dos países membros. Mais tarde, já no governo Maduro e com a forte emigração posta em marcha, a Venezuela, em agosto de 2017, teve seus direitos políticos suspensos do bloco por ruptura da ordem democrática, o que dificultava qualquer saída normativa via Acordo.

$\mathrm{Na}$ ausência de amparo legal por essa via, os venezuelanos adotaram a estratégia de ingressar no Brasil como solicitantes de refúgio, de forma a assegurar o imediato acolhimento, uma vez que o Brasil é signatário Convenção de Genebra sobre refugiados. Contudo, como já era imaginado, e posteriormente confirmado pela pesquisa de Simões et al (2017), a maioria dos deslocamentos efetivamente não ocorreram em função de fundado temor de perseguição, seja por parte de governo venezuelano, de paramilitares ou milícias, que pudesse assegurá-los a condição de refugiados. Essa situação colocava o governo brasileiro ante dois dilemas: o primeiro o de não possuir estrutura administrativa para analisar todos os processos em tempo razoavelmente hábil; o segundo de que, ao final da análise, a solicitação de refúgio teria o pedido negado, o que implicaria em ter que deportá-los, mesmo tendo claro a dimensão da crise econômica, social e política do outro lado da fronteira.

Nesse sentido, foi necessário criar uma normativa que permitisse a acolhida dos imigrantes venezuelanos no Brasil de forma regular, sem que isso gerasse um problema geopolítico com a Venezuela, dado que o governo Maduro insistia/insiste em negar a existência de qualquer tipo de crise em seu país. Assim, após alguns malabarismos, foi editada, pelo Conselho Nacional de Imigração (CNIg), em 02/03/2017, a Resolução Normativa (RN) 126, com o seguinte teor:

Art. $1^{\circ}$ Poderá ser concedida residência temporária, por um prazo de até 2 anos, ao estrangeiro que tenha ingressado no território brasileiro por via terrestre e seja nacional de país fronteiriço, para o qual ainda não esteja em vigor o Acordo de Residência para Nacionais de Estados Partes do MERCOSUL e países associados. (BRASIL, 2017c). 
Na prática, a medida estava voltada aos venezuelanos, mas poderia ser estendida aos nacionais da Guiana, Guiana Francesa e Suriname, caso esses manifestassem interesse pelo acolhimento no Brasil. Desse modo, os venezuelanos passaram a ter outro amparo legal, além da solicitação de refúgio, para viver em situação regular no país. Assim, paulatinamente, os pedidos de residência temporária ganhavam expressão em comparação com as solicitações de refúgio, embora tenham permanecido em volumes menores.

Com a edição da nova lei de migração, Lei 13.445, em 24/05/2017 (BRASIL, 2017b), e sua posterior regulamentação, através do Decreto 9.199, em 20/11/2017 (BRASIL, 2017a), foi necessária nova edição da resolução para adequação da norma ao novo marco jurídico, de modo que os Ministérios da Justiça, Extraordinário de Segurança Pública, Relações Exteriores e Trabalho, em conjunto, elaborassem a Portaria Interministerial $n^{\mathbf{o}}$ 9, de 14/03/2018 (BRASIL, 2018).

A Portaria trouxe avanços em relação a alguns pontos não previstos na RN 126, podendo ser destacados os seguintes aspectos: a questão da documentação para os migrantes indígenas e não indígenas; a possibilidade de os venezuelanos requererem, após dois anos, a residência por prazo indeterminado; e a explicitação da possibilidade do exercício de atividade laboral no mercado de trabalho formal tão logo fossem regularizados, o que na prática ocorre num curto espaço de tempo.

Atualmente tramita no âmbito do CNIg e do Comitê Nacional para os Refugiados (CONARE) a proposta de Resolução Conjunta para que seja concedida autorização de residência, associada a questão laboral, à solicitante de reconhecimento da condição de refugiado junto ao CONARE. Essa Resolução, uma vez aprovada, permitirá que os migrantes que: tenham solicitado refúgio até o dia 20 de novembro de 2017, possuam Carteira de Trabalho e Previdência Social com anotação de contrato até àquela data e não possuam outra autorização de residência que possibilite o exercício de atividade laboral, possam alterar o status da solicitação de refúgio para migração laboral. Dados da RAIS sinalizam que aproximadamente 2500 venezuelanos atenderiam a essas condições e seriam beneficiados com a mudança do status migratório solicitado.

Todas essas medidas normativas foram e são importantes, pois buscaram, tempestivamente, acolher a migração venezuelana de forma regular. No entanto, a edição da Portaria Interministerial $n^{\circ} 9$ não teria sido necessária, caso a nova lei de migração tivesse a parte que trata do visto humanitário regulamentada. Essa regulamentação facilitaria bastante 
não só a vida dos venezuelanos, como também de futuras nacionalidades que venham a se deparar com situação semelhante, de forma a evitar que as questões dessa natureza sejam tratadas caso a caso.

O papel do governo e das organizações sociais/internacionais

A intensificação dos fluxos e a incapacidade das autoridades locais em dar respostas adequadas, fosse no nível estadual ou nos municipais, produziram uma crise humanitária sem precedentes no país. No município de Pacaraima os mais atingidos eram os imigrantes da etnia Warao que viviam em ruas próximas ao terminal rodoviário. Para os não indígenas o município, basicamente, servia de passagem. Em Boa Vista os problemas atingiam de forma indiscriminada indígenas e não indígenas. Falta de moradia e alimentação adequadas e as dificuldades de acesso ao mercado de trabalho restrito, como já assinalado, eram características das mazelas vividas pelos imigrantes venezuelanos.

Do início do incremento dos fluxos migratórios até o fim de 2017, a participação da Igreja Católica, de Organizações não Governamentais, do Alto Comissariado das Nações Unidas para os Refugiados e de parte das populações locais foi decisiva no acolhimento dos venezuelanos, sobretudo para assegurar um mínimo de alimentos e abrigos precários para parcela dos migrantes. A atuação dos governos estadual e municipais era muito tímida e sempre muito voltada a denunciar a ameaça que representava o impacto migração nos serviços públicos básicos, em especial, no de saúde.

Grande parte da demora no enfrentamento da questão residiu no fato de não existir instância que faça a gestão das políticas migratórias, hoje dispersa pelos Ministérios da Justiça, Trabalho e Relações Exteriores, além de não haver ações integradas com os governos estaduais e municipais. Essa fragmentação faz com que as respostas governamentais no acolhimento e integração de fluxos migratórios mais intensos sejam sempre reativas, intempestivas e precárias, a respeito do que já havia acontecido com os haitianos, entre 2010 e 2011, no Acre e Amazonas.

Buscando finalmente dar resposta à crise humanitária, o governo federal adotou em 2018 as seguintes medidas:

i) criou um grupo de trabalho, coordenado pelo Ministério da Defesa, para efetivamente tratar a questão migratória em Roraima; 
ii) reeditou nova resolução normativa para conceder visto de residência temporária aos venezuelanos;

iii) aprovou Medida Provisória destinando R\$ 190 milhões para ser aplicado em medidas de acolhimento;

iv) firmou acordo de cooperação com o ACNUR para a implantação de novos abrigos e fornecimento de alimentação para os imigrantes;

v) propôs incentivar a interiorização dos imigrantes que assim o desejarem; e

vi) iniciou campanha de vacinação da população venezuelana em Roraima.

A partir da chegada dos recursos financeiros, algumas dessas iniciativas surtiram efeito, como a ampliação dos números de abrigos em Pacaraima e Boa Vista, serão sete apenas em 2018, o que melhorou muitíssimo as condições de abrigamento e alimentação dos migrantes; e o programa de vacinação avançou bastante. Por outro lado, o processo de interiorização segue tímido, cerca de 4.000 pessoas foram levadas para outros estados do país, como São Paulo, Rio Grande do Sul, Amazonas, Rio de Janeiro, Paraíba, Mato Grosso, Paraíba e Distrito Federal.

Mesmo tendo implementado essas medidas, o governo federal assistiu forte reação, sobretudo da governadora de Roraima, $\mathrm{Sr}^{\mathrm{a}}$ Suely Campos, que reiterou a necessidade do fechamento da fronteira com a Venezuela, denunciou que os serviços públicos estaduais estavam sobrecarregados por conta da migração e que não havia recebido repasse financeiro da União. Tudo indica que a reação dos poderes locais estava associada ao fato de parcela principal dos recursos ter sido repassada ao Ministério da Defesa e não ao estado e municípios.

Enfim, a dimensão da disputa política, sobretudo em ano de eleições7, seguiu pautando o enfrentamento da questão migratória em Roraima, em detrimento de ações mais efetivas de acolhida e integração.

\section{Considerações Finais}

\footnotetext{
${ }^{7}$ A atual governadora e o Senador Romero Jucá não conseguiram se reeleger no pleito do dia 03/10/2018 e atribuíram parte da derrota à migração venezuelana.
}

Revista de Estudos e Pesquisas sobre as Américas V.13 N.1 2019 ISSN: 1984-1639 
As crises política, econômica e social na Venezuela, ao colocarem a emigração como uma das principais estratégias na superação dos problemas, acabaram por gerar crises humanitárias nos dois lados da fronteira.

Num primeiro momento, as autoridades nos níveis municipais (Pacaraima e Boa Vista) e estadual encararam a questão com elevado grau de negligência, além de procurar tirar alguma vantagem do poder central, solicitando aportes financeiros numa proporção maior do que os efetivamente necessários. A tática utilizada era sobre-estimar a presença de imigrantes, aumentado de forma estupenda o número de pessoas que ingressavam no estado de Roraima (500 pessoas ao dia). Aqui deve ser salientado que, se toda a emigração estimada permanecesse em Pacaraima, bastariam 24 dias para que a população local fosse superada. Em Boa Vista, de meados de 2016 à metade de 2017, existia um número mágico de 30000 venezuelanos vivendo na cidade, volume que não se alterava, mesmo com a alegação de que 400/500 indivíduos chegavam a cada dia. Se as cifras fossem verdadeiras, os migrantes deveriam ser, no período mencionado, 1825008.

Como tentou-se demonstrar aqui, apesar de não estarem sistematizadas, as informações existiam. Todavia, desinformar servia à causa de quem queria tirar algum proveito da situação.

Uma vez que os recursos não chegavam na proporção solicitada, e a partir da real incapacidade de lidar com os fluxos que aportavam ao estado, as autoridades locais passaram a: atacar a migração, colocando-a como indesejada e aos imigrantes como o "outro" que estava ali para ameaçar a ordem constituída, à medida que colapsavam os serviços públicos9; a solicitar o fechamento da fronteira.

Não obstante a pesquisa de Simões et al. (2017), em agosto de 2017, ter demonstrado que os números estavam inflados e que a migração tinha um grande potencial, fosse pela formação educacional, fosse pela disponibilização de força de trabalho qualificada para o país, sobretudo porque parcela expressiva dos migrantes concordavam em se interiorizar, as autoridades locais seguiam desgastado a imagem dos venezuelanos. No outro plano, a instância federal não agiu para mitigar o problema, apesar de possuir um diagnóstico e uma possível solução apontada.

\footnotetext{
${ }^{8}$ Como já demonstrado, o que de fato ocorria era uma movimentação intensa, de entradas e saídas, associada aos deslocamentos pendulares para compras de bens de primeira necessidade no lado brasileiro, turismo e trânsito.

${ }^{9}$ Nesse ponto os venezuelanos já estavam estigmatizados.
} 
Isto permite inferir que os entes federados não atuaram de forma coordenada para enfrentar os desafios colocados por questões migratórias dessa natureza. O episódio com os haitianos já havia revelado essa falta de coordenação. Apenas ao final do ano de 2017, início de 2018 que o poder central passou a atuar, através de parcerias com os organismos internacionais (ACNUR/OIM), tendo o protagonismo do Ministério da Defesa, aportou R\$ 190 milhões, visando, principalmente, construir abrigos, distribuir alimentos e vacinar os imigrantes.

Contudo, como os governos locais passaram a exercer papel secundário no trato da questão, foram intensificados os pronunciamentos contrários à presença venezuelana e reiterada a solicitação de fechamento de fronteira. Dessa vez, com pedido na justiça federal 10. Os efeitos práticos dessas medidas foi o acirramento das manifestações violentas contra os imigrantes, que culminaram nas agressões ocorridas no município de Pacaraima, quando os venezuelanos tiveram que fugir de volta para o lado venezuelano, além do assassinato de um brasileiro e um migrante em Boa Vista

Esses episódios fizeram com que alguns poucos venezuelanos buscassem retornar para o seu país, como noticiado na imprensa (G1, 2018b). Mais uma vez, as autoridades da Venezuela e de Roraima buscaram tirar proveito político da situação, o que reforça a visão de que o menos importante são as vidas dos migrantes, seu estado emocional e a exposição a vulnerabilidades, nos dois lados da fronteira.

Por fim, resta evidente que a fragmentação na coordenação das políticas migratórias no país, que se encontra compartilhada entre três ministérios (MRE, MJ e MTb), dificulta o enfretamento de questões dessa magnitude, fato que é agravado pela falta de sintonia entre os entes federados nas três instâncias de poder. Saídas possíveis para contornar esse engessamento, poderiam passar pela centralização na coordenação das políticas e na criação de uma espécie de "Defesa Civil" migratória, pronta para atuar em casos semelhantes aos dos haitianos e venezuelanos, mobilizando rapidamente as condições de abrigamento, distribuição de alimentos e cuidados médicos, até que medidas para a regularização dos fluxos e integração dos imigrantes fossem adotadas.

\section{Referências}

\footnotetext{
${ }^{10}$ Embora o governo estadual tenha tido uma primeira sentença favorável, o Supremo Tribunal Federal cassou a liminar e proibiu o fechamento da fronteira.
}

Revista de Estudos e Pesquisas sobre as Américas V.13 N.1 2019 ISSN: 1984-1639 
800 NOTICIAS. Disponível em: http://800noticias.com/especial-el-mapa-de-la-oleadamigratoria-de-los-venezolanos-que-huyen-de-la-crisis. Acesso em 07/10/2018.

BRASIL Ministério da Justiça. Portaria Interministerial $n^{o}$ 9, de 14 de março de 2018. Disponível em: https://lex.com.br/legis_27624738_PORTARIA_INTERMINISTERIAL_N_9_DE_14_DE_ MARCO_DE_2018.aspx. Acesso em: 11/10/2018.

BRASIL Presidência da República. Decreto 9.199, de 20 de novembro de 2017. Disponível em: https://presrepublica.jusbrasil.com.br/legislacao/522434860/decreto-9199-17. Acesso em: $15 / 10 / 2018$.

BRASIL Presidência da República. Lei 13.445, de 24 de maio de 2017. Disponível em: http://www.planalto.gov.br/ccivil_03/_ato2015-2018/2017/lei/L13445.htm. Acesso em: $15 / 10 / 2018$.

BRASIL Ministério do Trabalho, Conselho Nacional de Imigração, Resolução Normativa $n^{o}$ 126. Disponível em: http://migramundo.com/cnig-reedita-concessao-de-residenciatemporaria-de-migrantes-de-paises-fronteiricos-ao-brasil/. Acesso em: 15/10/2018.

COLOMBO, Silvia. Exxodo da Venezuela se distingue de outros da região por volume e rapidez. Disponível em: https://www1.folha.uol.com.br/mundo/2018/09/exodo-da-venezuelase-distingue-de-outros-da-regiao-por-volume-e-rapidez.shtml. Acesso em:07/10/2018.

DEPARTAMENTO de Polícia Federal Sistema Nacional de Cadastro e Registros de Estrangeiros (SINCRE), 2018. MICRODADOS. Disponível em: http://obmigra.mte.gov.br/index.php/microdados. Acesso em: 15/10/2018.

G1 ONU diz que quase 2 milhões de pessoas deixaram a Venezuela desde 2015. Disponível em: $\quad$ https://g1.globo.com/mundo/noticia/2018/10/01/onu-diz-que-quase-2-milhoes-depessoas-deixaram-a-venezuela-desde-2015.ghtml. Acesso em: 15/10/2018.

G1 Mais de 104 imigrantes em Roraima são repatriados com apoio da igreja venezuelana: terão comida emprego. Disponível em: file:///G:/1.Backup_PC/TADEU/ARTIGOS/PUC_LIMA/Textos/Mais\%20104\%20imigrantes $\%$ 20em\%20Roraima\%20são\%20repatriados $\% 20$ com $\% 20$ apoio $\% 20 \mathrm{de} \% 20$ igreja\%20venezuel ana_\%20'terão\%20comida\%20e\%20emprego'\%20_\%20Roraima\%20_\%20G1.pdf. Acesso em: 15/10/2018.

G1 Mapeamento aponta que 25 mil venezuelanos vivem em Boa Vista, diz prefeitura. Disponível em: https://g1.globo.com/rr/roraima/noticia/mapeamento-aponta-que-25-milvenezuelanos-vivem-em-boa-vista-diz-prefeitura.ghtml. Acesso em: 15/10/2018.

IBGE, Estimativas da população residente para os municípios e para as Unidades da Federação com data de referência de $1^{o}$ de julho de 2018. Disponível em: https://biblioteca.ibge.gov.br/visualizacao/livros/liv101609.pdf. Acesso em:15/10/2018.

JUBILUT, Liliana L., MADUREIRA, André L. Os desafios de proteção aos refugiados e migrantes forçados no marco de Cartagena + 30. REMHU - Revista Interdisciplinar da Mobilidade Humana, vol. 22, núm. 43, julho-dezembro, 2014, pp. 11-33. 
MILESI, Rosita. Refugiados e migrações forçadas:: uma reflexão aos 20 anos da Declaração de Cartagena Disponível em: http://www.justica.gov.br/central-deconteudo/estrangeiros/art_irmarosita.pdf/view. Acesso em 07/10/2018.

OBMIGRA Relatório Admissões e Demissões. Disponível em: http://obmigra.mte.gov.br/index.php/admissoes-e-demissoes. Acesso em: 15/10/2018.

OBMIGRA Relatório Relação Anual de Informações Sociais (RAIS). Microdados. Disponível em: http://obmigra.mte.gov.br/index.php/microdados. Acesso em: 15/10/2018.

OIM/MDH DTM Brasil n ${ }^{\circ} 1$ O Monitoramento do Fluxo Migratório Venezuelano. Disponível em:

https://robuenosaires.iom.int/sites/default/files/Informes/DTM/MDH_OIM_DTM_Brasil_N1. pdf. Acesso em: 15/10/2018.

SILVA, João C. J. et al. Os fluxos migratórios mistos e os entraves à proteção aos refugiados. REBEP - R. bras. Est. Pop., Belo Horizonte, v.34, n.1, p.15-30, jan./abr. 2017.

SIMÕES, Gustavo F. Perfil sociodemográfico e laboral da imigração venezuelana no Brasil. Gustavo da Frota Simões (organizador). Curitiba: CRV, 2017. 112 p.

\section{A Migração Venezuelana no Brasil: crise humanitária, desinformação e os aspectos normativos}

\section{Resumo}

As crises política, social e econômica que vêm afetando a Venezuela, e intensificadas na segunda metade da atual década, colocou emigração internacional como alternativa de sobrevivência para aproximadamente dois milhões de venezuelanos, sendo o Brasil um entre os muitos dos destinos desses migrantes. Os graves fatores geradores desses deslocamentos populacionais acabaram por se traduzir numa verdadeira crise humanitária. A partir desse olhar, a proposta deste artigo, que entende esses movimentos como migração laboral forçada, ante à escassez de referências bibliográficas, foi recorrer às matérias jornalísticas, a alguns resultados de levantamentos estatísticos levados a campo e aos registros administrativos para buscar traçar um panorama sobre a trajetória e inserção desses imigrantes na sociedade de destino, pontuando como (des)informações disseminadas pelas autoridades locais, via de regra, superestimavam os volumes dos fluxos migratórios, serviram para criar uma imagem negativa dos imigrantes, gerando alguns episódios de agressões. Tudo isso num cenário de falta de coordenação entre os entes federados na condução de políticas migratórias adequadas.

Palavras-chaves: imigração venezuelana; crise humanitária; políticas migratórias;, Brasil.

\section{La Migración Venezolana en Brasil: crisis humanitaria, la desinformación y aspectos regulatorios}

\section{Resumen}

Las crisis políticas, sociales y económicas que vienen afectando a Venezuela -las cuales se intensificaron en la segunda mitad de la década actual- han impulsado la migración internacional como una alternativa para la supervivencia de unos dos millones de venezolanos que tienen a Brasil como uno de sus muchos destinos. Los graves factores que generaron estos desplazamientos desencadenaron una verdadera crisis humanitaria. Desde esa perspectiva, teniendo en cuenta la escasez de referencias bibliográficas y en el entendido de que esos movimientos son una migración de trabajo forzada, el propósito de este artículo se ha centrado en esbozar la trayectoria y la inserción de estos inmigrantes en la sociedad de destino, con base en las noticias publicadas en periódicos, algunas pocas encuestas estadísticas y registros administrativos, señalando de qué manera la 
situación de desinformación que se expandió, bajo la responsabilidad de las autoridades locales, hacía aumentar los volúmenes de flujos migratorios generando una imagen negativa de los inmigrantes, produciendo incluso episodios de agresiones. Todo esto en un escenario de falta de coordinación entre las instancias gubernamentales respecto de la implementación de políticas migratorias apropiadas.

Palabras clave: inmigración venezolana, crisis humanitaria, políticas migratorias, Brasil

\title{
The Venezuelan Migration in Brazil: humanitarian crisis, misinformation and regulatory aspects
}

\begin{abstract}
The political, social and economic crises that come affecting Venezuela, and intensified in the second half of the current decade, put international migration as an alternative to survival for about 2 million of Venezuelans, with Brazil being one among the many of the targets of these migrants. This serious situation eventually translates into a real humanitarian crisis. From that look, the purpose of this article, to understand these movements as forced labour migration, faced with the shortage of references, It was resorting to journalistic material, some results of statistical surveys conducted field and administrative records to get an overview about the trajectory and insertion of these immigrants in the target society, pointing out how the misinformation spread by local authorities, increased volumes of migratory flows, served to create a negative image of immigrants, generating some episodes of aggression. All this against a background of lack of coordination between the federated entities in the conduct of appropriate migration policies.
\end{abstract}

Keys word: Venezuelan immigration, humanitarian crisis, migration policies, Brazil. 